\title{
Enantioselective Conjugate Addition of Anthrone to Nitroalkenes Catalyzed by Binaphthyl-Modified Organocatalyst ${ }^{\dagger}$
}

\author{
Hyun Joo Lee, Young Mi Chae, and Dae Young Kim* \\ Department of Chemistry, Soonchunhyang University, Asan, Chungnam 336-745, Korea. *E-mail: dyoung@sch.ac.kr \\ Received February 26, 2011, Accepted April 1, 2011
}

Key Words : Anthrones, Asymmetric catalysis, Nitroalkens, Conjugate addition, Organocatalysis

Anthrone and its derivatives are important compounds in biochemical and medicinal applications and material science. ${ }^{1}$ Thus, the development of asymmetric synthetic methods for the preparation of anthrone derivatives appears as a valuable topic in organic chemistry. The Michael addition reaction is widely recognized as one of the most general and versatile methods for formation of C-C bonds in organic synthesis, ${ }^{2}$ and the development of enantioselective catalytic protocols for this reaction has been subject of intensive research. ${ }^{3}$ Michael reaction of nucleophiles to nitroalkenes represents a direct and most appealing approach to chiral nitroalkanes that are versatile intermediates in organic synthesis, which can be transformed into an amine, nitrile oxide, ketone, carboxylic acid, hydrogen etc. ${ }^{4}$ Until now, several examples of organocatalyzed asymmetric conjugate addition reactions of anthrone have been developed. ${ }^{5}$ Recently, Shi and Yuan groups have reported catalytic asymmetric conjugate addition of anthrone to nitroalkenes catalyzed by cinchona alkaloid derivatives. ${ }^{6}$ There are still a drawback in the previously reported procedures, such as low temperatures for high enantioselectivity.

As part of a research program related to the development of synthetic methods for the enantioselective construction of stereogenic carbon centers, ${ }^{7}$ we recently reported chiral amine bifunctional organocatalyst to be a highly selective catalyst for the enantioselective addition reaction of active methines. ${ }^{8}$ We envisioned that the assembly of a structurally welldefined chiral 1,2-diamine and binaphthyl scaffold with a thiourea or squaramide motif could constitute a new class of bifunctional organocatalyst. In this communication, we wish to describe the direct enantioselective conjugate addition reaction of anthrone with nitroalkenes catalyzed by binaphthyl-modified organocatalysts bearing both central and axial chiral elements.

In an attempt to validate the feasibility of the organocatalytic enantioselective conjugate addition reaction of anthrone, we initially investigated the reaction system with anthrone $\mathbf{1}$ and $\beta$-nitrostyrene $2 \mathbf{a}$ in the presence of $10 \mathrm{~mol} \%$ of catalyst in toluene at room temperature. We first examined the impact of the structure of catalysts on enantioselectivities (Table 1, entries 1-8). Binaphthyl-modified chiral bifunctional organocatalysts I-VI bearing both central and axial chiral elements effectively

This paper is dedicated to Professor Eun Lee on the occasion of his honourable retirement.
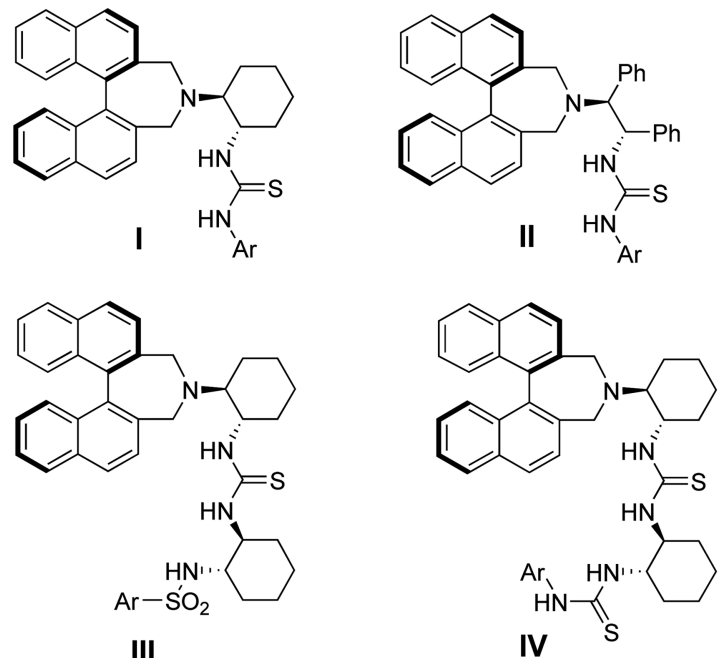

III
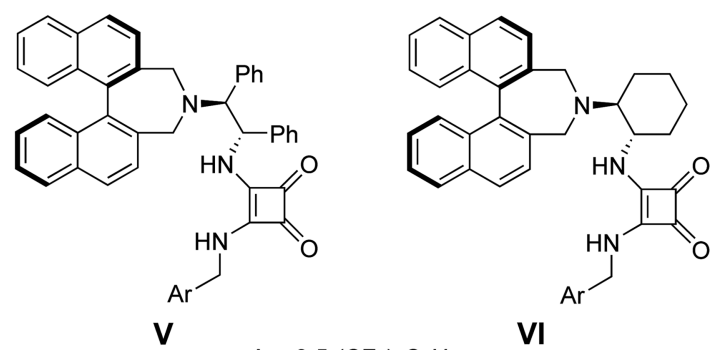

$\mathrm{Ar}: 3,5-\left(\mathrm{CF}_{3}\right)_{2} \mathrm{C}_{6} \mathrm{H}_{3}$

VI

Figure 1. Structure of chiral binaphthyl-modified organocatalysts

promoted the addition in high yield with high enantioselectivity (60-91\% ee). Catalyst VI gave the desired product 3a with high enantioselectivity (Table 1 , entry 6). A survey of the reaction media indicated that many common solvents, such as benzene, $n$-hexane, $p$-xylene, DCM, THF, diethyl ether, DMSO, and acetonitrile (Table 1, entries 7-14), were well tolerated in this conjugate addition with low to moderate enantioselectivities. Among the solvents probed, the best results ( $83 \%$ yield and $91 \%$ ee, Table 1 , entry 6$)$ were achieved when the reaction was conducted in toluene (Table 1, entry 6). Lowering the temperature to $0{ }^{\circ} \mathrm{C}$ with catalyst VI decreased the enantioselectivity (Table 1, entry 15). Even though the catalyst loading was reduced to $1 \mathrm{~mol} \%$, the yield and enantioselectivity still remains at high level albeit with a slight drop of catalytic activity (Table 1, entry 17). Absolute configuration of Michael adducts 3a was determined by 
Table 1. Optimization of the reaction conditions

\begin{tabular}{|c|c|c|c|c|c|}
\hline 1 & & $=\mathrm{NO}^{\mathrm{NO}_{2}}$ & $\frac{\mathrm{t} .(10 \mathrm{~mol}}{\text { solvent, } \mathrm{rt}}$ & & $\mathbf{a}$ \\
\hline entry & cat. & solvent & time (h) & yield $(\%)^{a}$ & ee $(\%)^{b}$ \\
\hline 1 & I & Toluene & 24 & 65 & 69 \\
\hline 2 & II & Toluene & 48 & 65 & 79 \\
\hline 3 & III & Toluene & 22 & 85 & 61 \\
\hline 4 & IV & Toluene & 25 & 78 & 63 \\
\hline 5 & $\mathbf{V}$ & Toluene & 60 & 72 & 60 \\
\hline 6 & VI & Toluene & 20 & 83 & 91 \\
\hline 7 & VI & Benzene & 33 & 62 & 89 \\
\hline 8 & VI & $n$-Hexane & 48 & 45 & 49 \\
\hline 9 & VI & $p$-Xylene & 33 & 79 & 87 \\
\hline 10 & VI & $\mathrm{CH}_{2} \mathrm{Cl}_{2}$ & 48 & 78 & 87 \\
\hline 11 & VI & THF & 48 & 73 & 87 \\
\hline 12 & VI & $\mathrm{Et}_{2} \mathrm{O}$ & 72 & 50 & 79 \\
\hline 13 & VI & DMSO & 59 & 67 & 9 \\
\hline 14 & VI & $\mathrm{CH}_{3} \mathrm{CN}$ & 72 & 69 & 65 \\
\hline $15^{c}$ & VI & Toluene & 20 & 56 & 75 \\
\hline $16^{d}$ & VI & Toluene & 24 & 82 & 91 \\
\hline $17^{e}$ & VI & Toluene & 24 & 75 & 85 \\
\hline
\end{tabular}

${ }^{a}$ Isolated yield.

${ }^{b}$ Enantioselectivity was determined by chiral HPLC analysis with Chiralpak AS-H column.

${ }^{c}$ This reaction was carried out at $0{ }^{\circ} \mathrm{C}$.

${ }^{d} 5 \mathrm{~mol} \%$ catalyst loading.

${ }^{e} 1 \mathrm{~mol} \%$ catalyst loading.

Table 2. Enantioselective conjugate addition of anthrone to nitroalkenes

\begin{tabular}{clccc} 
& & & & \\
& & & & \\
\hline
\end{tabular}

${ }^{a}$ Isolated yield.

${ }^{b}$ Enantiomeric excess was determined by HPLC analysis using chiral columns (Chiralpak AS-H for 3a-3d, 3h, OD-H for 3e, 3g, and AD-H for 3f).

comparison of the optical rotation and chiral HPLC data with the literature values. ${ }^{6}$

To examine the generality of this protocol, we studied the conjugate addition reaction of anthrone 1 to various nitroalkenes 2. As demonstrated in Table 2, organocatalyst VI-catalyzed enantioselective conjugate addition reaction of anthrone $\mathbf{1}$ to various nitroalkenes $\mathbf{2 a - h}$ proved to be a general approach for the synthesis of chiral anthrone derivatives 3. Notably, good to high enantiomeric excess was obtained (up to $91 \%$ ee).

In conclusion, we have developed organocatalytic enantioselective conjugate addition reaction of anthrone to various nitroalkenes. The reaction was catalyzed by binaphthyl-modified organocatalysts and afforded the corresponding adducts in high yields and high enantioselectivities up to $91 \%$. Further details and application of this asymmetric Michael reaction of anthrone will be presented in due course.

\section{References}

1. (a) Iwaura, R.; Ohnishi-Kameyama, M.; Lizawa, T. Chem. Eur. J. 2009, 15, 3729. (b) Zuse, A.; Schmidt, D.; Baasner, S.; Böhm, K. J.; Müller, K.; Gerlach, M.; Günther, E. G.; Unger, E.; Prinz, H. J. Med. Chem. 2007, 50, 6059.

2. Perlmutter, P. Conjugate Addition Reactions in Organic Synthesis; Pergamon: Oxford, 1992.

3. For recent reviews of asymmetric Michael addition reactions, see: (a) Berner, O. M.; Tedeschi, L.; Enders, D. Eur. J. Org. Chem. 2002, 1877. (b) Christoffers, J.; Baro, A. Angew. Chem. Int. Ed. 2003, 42,1688 .

4. (a) Ono, N. The Nitro Group in Organic Synthesis; Wiley-VCH: New York, 2001. (b) Ballini, R.; Petrini, M. Tetrahedron 2004, 60, 1017. (c) Czekelius, C.; Carreira, E. M. Angew. Chem. Int. Ed. 2005, 44, 612 .

5. (a) Shen, J.; Nguyen, T. T.; Goh, Y.-P.; Ye, W.; Fu, X.; Xu, J.; Tan, C.-H. J. Am. Chem. Soc. 2006, 128, 13692. (b) Alba, A.-N.; Bravo, N.; Moyano, A.; Rios, R. Tetrahedron Lett. 2009, 50, 3067. (c) Akalay, D.; Durner, G.; Gobel, M. W. Eur. J. Org. Chem. 2008, 2365.

6. (a) Shi, M.; Lei, Z.-Y.; Zhao, M.-X.; Shi, J.-W. Tetrahedron Lett. 2007, 48, 5743. (b) Liao, Y.-H.; Zhang, H.; Wu, Z.-j.; Cun, L.-F.; Zhang, X.-M.; Yuan, W.-C. Tetrahedron:Asymmetry 2009, 20, 2397. (c) Zea, A.; Alba, A.-N. R.; Bravo, N.; Moyano, A.; Rios, R. Tetrahedron 2011, 67, 2513.

7. (a) Mang, J. Y.; Kwon, D. G.; Kim, D. Y. J. Fluorine Chem. 2009, 130, 259. (b) Kang, S. H.; Kang, Y. K.; Kim, D. Y. Tetrahedron 2009, 65, 5676. (c) Mang, J. Y.; Kwon, D. G.; Kim, D. Y. Bull. Korean Chem. Soc. 2009, 30, 249. (d) Lee, N. R.; Kim S. M.; Kim, D. Y. Bull. Korean Chem. Soc. 2009, 30, 829. (e) Kim, E. J.; Kang, Y. K.; Kim, D. Y. Bull. Korean Chem. Soc. 2009, 30, 1437. (f) Kang, S. H.; Kim, D. Y. Bull. Korean Chem. Soc. 2009, 30,1439. (g) Kwon, B. K.; Kim, D. Y. Bull. Korean Chem. Soc. 2009, 30, 1441. (h) Kang, Y. K.; Kim, D. Y. Curr. Org. Chem. 2010, 14, 917. (i) Kang, S. H.; Kim, D. Y. Adv. Synth. Catal. 2010, 352, 2783. (j) Kang, Y. K.; Kim, S. M.; Kim, D. Y. J. Am. Chem. Soc. 2010, 132, 11847. (k) Lee, H. J.; Kim, J. H.; Kim, D. Y. Bull. Korean Chem. Soc. 2011, 32, 785. (1) Kang, Y. K.; Kim, D. Y. Tetrahedron Lett. 2011, 52, 2356.

8. (a) Kim, S. M.; Lee, J. H.; Kim, D. Y. Synlett 2008, 2659. (b) Jung, S. H.; Kim, D. Y. Tetrahedron Lett. 2008, 49, 5527. (c) Kang, Y. K.; Kim, D. Y. J. Org. Chem. 2009, 74, 5734. (d) Lee, J. H.; Kim, D. Y. Adv. Synth. Catal. 2009, 351, 1779. (f) Kwon, B. K.; Kim, S. M.; Kim, D. Y. J. Fluorine Chem. 2009, 130, 759. (g) Oh, Y.; Kim, S. M.; Kim, D. Y. Tetrahedron Lett. 2009, 50, 4674. (h) Moon, H. W.; Cho, M. J.; Kim, D. Y. Tetrahedron Lett. 2009, 50, 4896. (i) Kang, Y. K.; Kim, D. Y. J. Org. Chem. 2009, 74, 5734. (j) Lee, J. H.; Kim, D. Y. Adv. Synth. Catal. 2009, 351, 1779. (k) Lee, J. H.; Kim, D. Y. Synthesis 2010, 1860. (1) Moon, H. W.; Kim, D. Y. Tetrahedron Lett. 2010, 51, 2906. (m) Yoon, S. J.; Kang, Y. K.; Kim, D. Y. Synlett 2011, 420. (n) Moon, H. W.; Kim, D. Y. Bull. Korean Chem. Soc. 2011, 32, 291. 